\title{
Vapor-liquid equilibria at elevated pressures of binary mixtures of carbon dioxide with methyl salicylate, eugenol, and diethyl phthalate
}

\author{
Kong-Wei Cheng, Shin-Jien Kuo, Muoi Tang ${ }^{1}$, Yan-Ping Chen* \\ Department of Chemical Engineering, National Taiwan University, Taipei, Taiwan, ROC
}

Received 25 October 1999; received in revised form 20 April 2000; accepted 16 May 2000

\begin{abstract}
A semi-flow type apparatus was used to measure the vapor-liquid equilibria (VLE) of $\mathrm{CO}_{2}$ with methyl salicylate, eugenol, and diethyl phthalate binary mixtures at 308.15, 318.15, and $328.15 \mathrm{~K}$ over the pressure range from 1.4 to $13 \mathrm{MPa}$. New VLE data for these binary mixtures are presented and the Henry's constants were determined from these results. The Soave-Redlich-Kwong and the Peng-Robinson equations of state, and the van der Waals, Panagiotopoulos-Reid and Huron-Vidal mixing rules are used to correlate these VLE data. It is shown that both equations of state with the van der Waals mixing rules and two adjustable parameters give satisfactory correlation results. (C) 2000 Elsevier Science B.V. All rights reserved.
\end{abstract}

Keywords: Vapor-liquid equilibria; Binary mixture; Data

\section{Introduction}

The experimental determination of phase equilibrium data at high pressures for supercritical fluid systems is becoming more and more important because of increasing applications of dense gases. Carbon dioxide is often used for supercritical fluid extraction since it is nontoxic and it has relatively low critical temperature and pressure. The phase equilibrium data at high pressures for carbon dioxide with specialty chemicals or esters

\footnotetext{
* Corresponding author.

${ }^{1}$ Present address: Department of Chemical Engineering, Chinese Culture University, Taipei, Taiwan, ROC.
}

are not adequate in literature [1,2]. More experimental measurements for carbon dioxide with such compounds are required for thermodynamic modeling and future process design. In this work, a semi-flow apparatus was used to measure the high pressure vapor-liquid equilibria (VLE) for three binary systems of $\mathrm{CO}_{2}+$ methyl salicylate, $\mathrm{CO}_{2}+$ eugenol, and $\mathrm{CO}_{2}+$ diethyl phthalate. Methyl salicylate $\left(\mathrm{C}_{8} \mathrm{H}_{8} \mathrm{O}_{3}\right)$ and eugenol $\left(\mathrm{C}_{10} \mathrm{H}_{12} \mathrm{O}_{2}\right)$ are used as food additives. Diethyl phthalate $\left(\mathrm{C}_{12} \mathrm{H}_{14} \mathrm{O}_{4}\right)$ is used as the plasticizer in organic synthesis. The experiments were carried out at temperatures of $308.15,318.15$, and 328.15 $\mathrm{K}$. The pressure ranges from 1.4 to $13 \mathrm{MPa}$. The experimental data were tested for thermodynamic 
consistency. The VLE data of each isotherm were used to evaluate Henry's constants. The experimental results were also correlated using the Soave-Redlich-Kwong [3] and the PengRobinson [4] equations of state with various mixing rules. Optimal binary parameters are reported and satisfactory correlation results are presented.

\section{Experimental section}

\subsection{Chemicals}

Liquefied carbon dioxide was available with purity greater than $99.8 \mathrm{~mol} \%$ from San-Fu Chemical Co. (Taiwan). Methyl salicylate, eugenol, and diethyl phthalate were purchased from Merck Co. The purity of these chemicals is better than $99 \%$. No further purification of these chemicals was made. The pure compound properties were measured in this study, and the comparison with literature data is shown in Table 1. The refractive indices of the pure compounds were measured at $(293.15 \pm 0.1) \mathrm{K}$ by an Abbe refractometer, Atago 3T, with an accuracy of \pm 0.0001 . The densities of pure chemicals were measured at (293.15 or $294.15 \pm 0.1) \mathrm{K}$ using the Anton Paar DMA $60 / 602$ density meter with an accuracy of $\pm 1.0 \times 10^{-5} \mathrm{~g} \mathrm{~cm}^{-3}$. It is shown that the measured pure fluid properties agree well with literature data.

\subsection{Apparatus}

A semi-flow phase equilibrium apparatus, as shown in Fig. 1, was used in this study. The apparatus and experimental procedures are similar to those given by Lee and Chao [5]. The

Table 1

Comparison of the measured refractive indices and densities of pure fluids with literature data

\begin{tabular}{|c|c|c|c|c|c|}
\hline \multirow[t]{2}{*}{ Component } & \multicolumn{2}{|l|}{$n^{\mathrm{D}}(293.15 \mathrm{~K})$} & \multicolumn{2}{|c|}{$\rho\left(293.15 \mathrm{~K}, \mathrm{~g} \mathrm{~cm}^{-3}\right)$} & \multirow[t]{2}{*}{ Purity (mass $\%$ ) } \\
\hline & Experimental & Literature [18] & Experimental & Literature [18] & \\
\hline Methyl salicylate & 1.5358 & 1.5350 & 1.1838 & 1.1738 & $>99.0$ \\
\hline Eugenol & 1.5392 & 1.5405 & 1.0667 & 1.0652 & $>99.0$ \\
\hline Diethyl phthalate & $1.5012^{294.15 \mathrm{~K}}$ & $1.5000^{294.15 \mathrm{~K}}$ & 1.1179 & 1.1175 & $>99.0$ \\
\hline
\end{tabular}

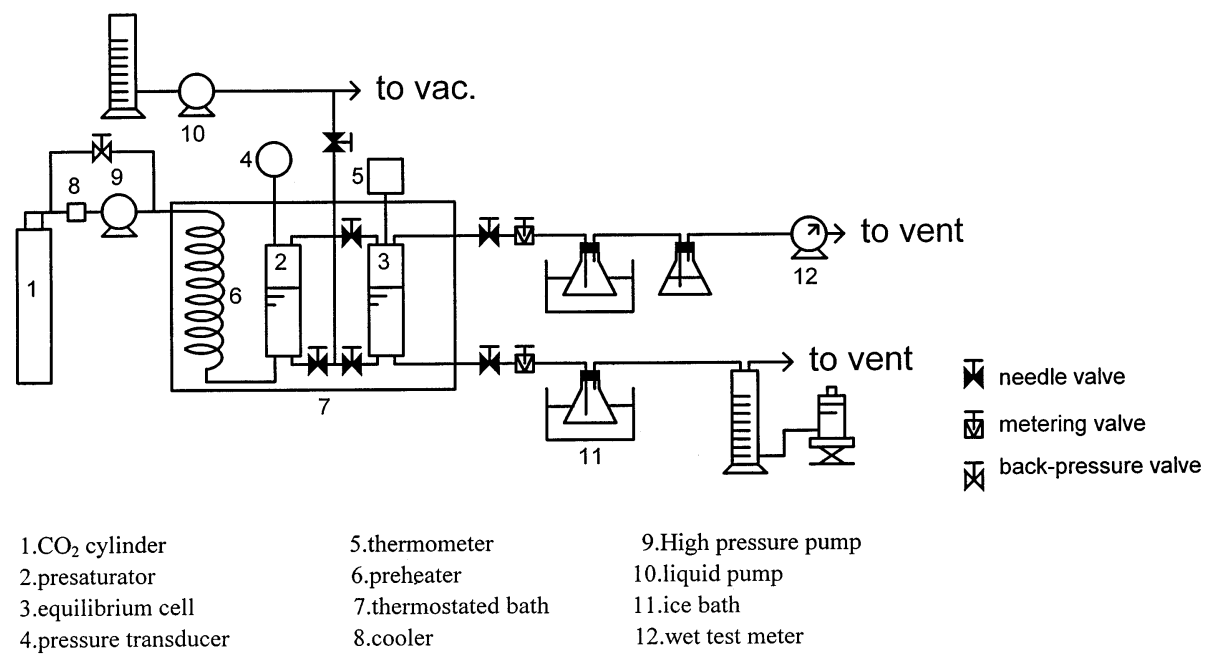

Fig. 1. Schematic diagram of the experimental apparatus. 
Table 2

Experimental VLE results for the binary mixture of $\mathrm{CO}_{2}(1)+$ methyl salicylate(2)

\begin{tabular}{|c|c|c|c|}
\hline \multirow[t]{2}{*}{ Pressure (MPa) } & \multicolumn{2}{|c|}{ Composition } & \multirow{2}{*}{$\begin{array}{l}\text { Equilibrium constant } \\
K_{1}\end{array}$} \\
\hline & $x_{1}$ & $y_{1}$ & \\
\hline \multicolumn{4}{|l|}{$T=308.15 \mathrm{~K}$} \\
\hline 1.515 & 0.1097 & 0.9998 & 9.114 \\
\hline 2.954 & 0.2076 & 0.9998 & 4.816 \\
\hline 4.238 & 0.3304 & 0.9997 & 3.026 \\
\hline 5.590 & 0.4374 & 0.9997 & 2.286 \\
\hline 6.979 & 0.5704 & 0.9996 & 1.752 \\
\hline 8.375 & 0.6825 & 0.9990 & 1.464 \\
\hline \multicolumn{4}{|l|}{$T=318.15 \mathrm{~K}$} \\
\hline 1.567 & 0.0954 & 0.9996 & 10.478 \\
\hline 2.910 & 0.1887 & 0.9996 & 5.297 \\
\hline 4.324 & 0.2807 & 0.9996 & 3.561 \\
\hline 5.600 & 0.3760 & 0.9995 & 2.658 \\
\hline 6.858 & 0.4577 & 0.9995 & 2.184 \\
\hline 8.272 & 0.5508 & 0.9994 & 1.814 \\
\hline 9.961 & 0.6387 & 0.9963 & 1.560 \\
\hline 11.236 & 0.6787 & 0.9921 & 1.462 \\
\hline \multicolumn{4}{|l|}{$T=328.15 \mathrm{~K}$} \\
\hline 1.549 & 0.0878 & 0.9997 & 11.386 \\
\hline 2.859 & 0.1635 & 0.9997 & 6.114 \\
\hline 4.238 & 0.2437 & 0.9996 & 4.102 \\
\hline 5.634 & 0.3199 & 0.9996 & 3.125 \\
\hline 6.961 & 0.4057 & 0.9994 & 2.463 \\
\hline 9.340 & 0.5124 & 0.9990 & 1.950 \\
\hline 10.064 & 0.5429 & 0.9987 & 1.840 \\
\hline 12.098 & 0.6341 & 0.9949 & 1.569 \\
\hline 13.201 & 0.6657 & 0.9868 & 1.482 \\
\hline
\end{tabular}

apparatus consists of the supercritical fluid feed, the equilibrium and the analysis sections.

Pure $\mathrm{CO}_{2}$ from a cylinder was liquefied through a cooler at $-6.5^{\circ} \mathrm{C}$. It was then compressed by a metering pump (ConstaMetric $3200 \mathrm{P} / \mathrm{F}$, LCD Analytical Inc.), and was heated through a preheating coil immersing in a water bath before introducing into the equilibrium cells. To improve the fluid compression, each head of the pump was equipped with a cooling jacket in which aqueous alcohol at $-6.5^{\circ} \mathrm{C}$ was used. A desired pressure was set in the experiment and was maintained at this value using a back pressure regulator (Tescom) during the measurements.

One pre-saturation cell and an equilibrium cell, each with a volume of $300 \mathrm{~cm}^{3}$, were used in this study. The cells (Whitey) were made by stainless steel and were immersed in a water bath. The experimental temperature and pressure were measured using a calibrated quartz thermometer (INS), and a calibrated pressure gauge (Heise). The accuracy for temperature measurement is \pm $0.1 \mathrm{~K}$, and that for pressure measurement is \pm $0.02 \mathrm{MPa}$. The metering valves (Autoclave) and needle valves (Whitey) were also maintained at the experimental temperature to ensure equilibrium conditions.

The solvent component from either a liquid or vapor sample was collected in a flask cooled by an ice bath. The volume of the solute in the vapor phase was measured by a wet test meter (Ritter, TG50), and that of the liquid phase was determined by measuring the volume displaced in a

Table 3

Experimental VLE results for the binary mixture of $\mathrm{CO}_{2}(1)+$ eugenol(2)

\begin{tabular}{|c|c|c|c|}
\hline \multirow[t]{2}{*}{ Pressure (Mpa) } & \multicolumn{2}{|c|}{ Composition } & \multirow{2}{*}{$\begin{array}{l}\text { Equilibrium constant } \\
K_{1}\end{array}$} \\
\hline & $x_{1}$ & $y_{1}$ & \\
\hline \multicolumn{4}{|l|}{$T=308.15 \mathrm{~K}$} \\
\hline 1.480 & 0.1160 & 0.9988 & 8.610 \\
\hline 2.825 & 0.2417 & 0.9987 & 4.132 \\
\hline 4.252 & 0.3695 & 0.9987 & 2.703 \\
\hline 5.617 & 0.4911 & 0.9987 & 2.034 \\
\hline 7.051 & 0.6232 & 0.9986 & 1.602 \\
\hline 8.410 & 0.7576 & 0.9837 & 1.298 \\
\hline \multicolumn{4}{|l|}{$T=318.15 \mathrm{~K}$} \\
\hline 1.480 & 0.1006 & 0.9988 & 9.928 \\
\hline 2.825 & 0.1922 & 0.9987 & 5.196 \\
\hline 4.211 & 0.2910 & 0.9986 & 3.432 \\
\hline 5.548 & 0.3951 & 0.9986 & 2.527 \\
\hline 7.113 & 0.5059 & 0.9986 & 1.974 \\
\hline 8.361 & 0.5926 & 0.9985 & 1.685 \\
\hline 9.761 & 0.6921 & 0.9959 & 1.439 \\
\hline \multicolumn{4}{|l|}{$T=328.15 \mathrm{~K}$} \\
\hline 2.845 & 0.1725 & 0.9986 & 5.789 \\
\hline 4.238 & 0.2552 & 0.9986 & 3.913 \\
\hline 5.652 & 0.3479 & 0.9986 & 2.870 \\
\hline 7.065 & 0.4389 & 0.9985 & 2.275 \\
\hline 8.416 & 0.5107 & 0.9985 & 1.955 \\
\hline 9.706 & 0.5816 & 0.9985 & 1.717 \\
\hline 11.236 & 0.6562 & 0.9961 & 1.518 \\
\hline 12.512 & 0.7040 & 0.9904 & 1.407 \\
\hline
\end{tabular}


Table 4

Experimental VLE results for the binary mixture of $\mathrm{CO}_{2}(1)+$ diethyl phthalate(2)

\begin{tabular}{|c|c|c|c|}
\hline \multirow[t]{2}{*}{ Pressure (Mpa) } & \multicolumn{2}{|c|}{ Composition } & \multirow{2}{*}{$\begin{array}{l}\text { Equilibrium constants } \\
K_{1}\end{array}$} \\
\hline & $x_{1}$ & $y_{1}$ & \\
\hline \multicolumn{4}{|l|}{$T=308.15 \mathrm{~K}$} \\
\hline 1.618 & 0.1674 & 0.9999 & 5.973 \\
\hline 2.859 & 0.2877 & 0.9999 & 3.475 \\
\hline 3.532 & 0.3481 & 0.9999 & 2.872 \\
\hline 4.307 & 0.4212 & 0.9999 & 2.374 \\
\hline 4.910 & 0.4710 & 0.9999 & 2.123 \\
\hline 5.669 & 0.5341 & 0.9999 & 1.872 \\
\hline 6.307 & 0.5647 & 0.9999 & 1.771 \\
\hline 6.996 & 0.6406 & 0.9999 & 1.561 \\
\hline 7.806 & 0.7077 & 0.9996 & 1.412 \\
\hline \multicolumn{4}{|l|}{$T=318.15 \mathrm{~K}$} \\
\hline 1.567 & 0.1409 & 0.9999 & 7.097 \\
\hline 2.894 & 0.2501 & 0.9999 & 3.998 \\
\hline 4.307 & 0.3659 & 0.9999 & 2.733 \\
\hline 4.928 & 0.4077 & 0.9999 & 2.453 \\
\hline 5.652 & 0.4659 & 0.9999 & 2.146 \\
\hline 6.427 & 0.5161 & 0.9999 & 1.937 \\
\hline 7.134 & 0.5629 & 0.9999 & 1.776 \\
\hline 8.582 & 0.6400 & 0.9999 & 1.562 \\
\hline 9.599 & 0.6766 & 0.9990 & 1.477 \\
\hline 11.529 & 0.7338 & 0.9926 & 1.353 \\
\hline \multicolumn{4}{|l|}{$T=328.15 \mathrm{~K}$} \\
\hline 1.600 & 0.1332 & 0.9999 & 7.507 \\
\hline 2.859 & 0.2259 & 0.9999 & 4.426 \\
\hline 4.238 & 0.3181 & 0.9999 & 3.143 \\
\hline 5.617 & 0.4097 & 0.9999 & 2.441 \\
\hline 7.031 & 0.4973 & 0.9995 & 2.010 \\
\hline 8.272 & 0.5611 & 0.9994 & 1.781 \\
\hline 10.099 & 0.6375 & 0.9993 & 1.568 \\
\hline 11.098 & 0.6722 & 0.9990 & 1.486 \\
\hline 12.564 & 0.7134 & 0.9978 & 1.399 \\
\hline
\end{tabular}

column filled with water. The accuracy for these measurements is better than $\pm 0.25 \%$.

\section{Experimental procedures}

Pure liquid solvent was initially fed into the pre-saturation and equilibrium cells. Air in the cells was displaced by flushing with $\mathrm{CO}_{2}$. The two cells were maintained at a constant temperature in a water bath, and $\mathrm{CO}_{2}$ was charged into the cells at a desired pressure. After the phase equilibrium is reached, the vapor and liquid samples were expanded to atmospheric pressure, respectively, through the corresponding metering valves. The samples were then analyzed by the gravimetric method. The volume of the solute from the vapor and liquid phases were measured by a wet test meter and a water column, respectively. The minor amount of the condensate that vaporized into the gas phase is corrected by using its vapor pressure. At least three measurements were carried out to ensure that the composition in the liquid or gas phase had reached a stable value. The measured composition is with an accuracy better than $\pm 2 \%$ for the component with a smaller mol fraction in each phase.

\section{Results and discussion}

The measured equilibrium compositions and the corresponding equilibrium ratios ( $K$ values) for three binary mixtures of $\mathrm{CO}_{2}$ with methyl salicylate, eugenol and diethyl phthalate are presented in Tables 2-4, respectively. Graphical presentations of the experimental results are shown in Figs. $2-4$. The experimental data were tested for thermodynamic consistency using the $K$ value method $[6,7]$. The $K$ values are plotted against pressure for each binary mixture, and the results are shown in Figs. 5-7, respectively. According to the test using $K$ value method, the slope for each plot should be close to -1 in order to satisfy the thermodynamic consistency. It is observed from these figures that the experimental results of this study agree well with the thermodynamic consistency statement.

The solubility of carbon dioxide in three aromatic compounds at $328.15 \mathrm{~K}$ is shown in Fig. 8 . It is indicated by Jan and Tsai [8] that the methyl group in the benzene ring increases the solubility of carbon dioxide and the substituent hydroxy group shows the opposite effect. According to this explanation, we observe that at a given pressure carbon dioxide has the largest solubility in diethyl phthalate, and the least solubility in methyl salicylate. The solubilities of the three aromatic compounds in the vapor phase are not significant at low pressures. These solubilities increase dramatically at equilibrium pressure higher than the criti- 
Table 5

Parameters of the Krichevsky-Ilinskaya equation for three binary systems

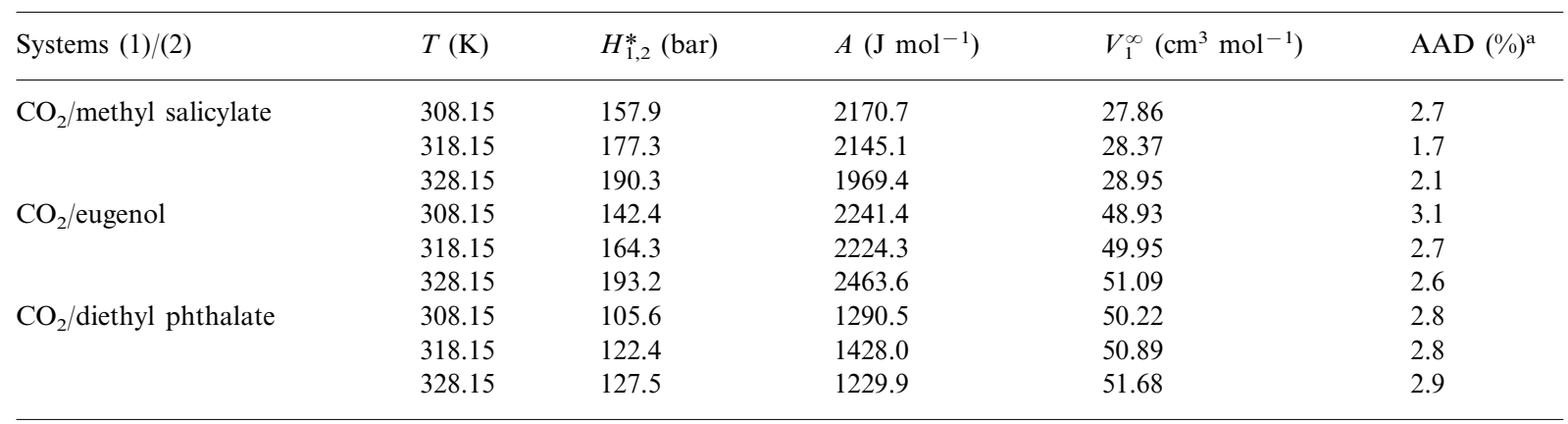

${ }^{\mathrm{a}} \operatorname{AAD}(\%)=(100 / n) \sum_{k=1}^{n}\left\{\left|\left(f_{1} / x_{1}\right)^{\mathrm{cal}}-\left(f_{1} / x_{1}\right)^{\exp }\right| /\left(f_{1} / x_{1}\right)^{\exp }\right\}_{k} \cdot$

cal point of carbon dioxide. Fig. 9 shows the solubility of three solutes in carbon dioxide. Diethyl phthalate has the largest molecular weight and the least solubility in the gas phase. The solubility of eugenol in the gas phase is higher than that of methyl salicylate owing to the smaller molecular associating effect of eugenol.

The Krichevsky-Ilinskaya (KI) equation [9] is generally applicable for the correlation of gas solubility data over a wide concentration range. Henry's constant is evaluated from the regression of the solubility data:

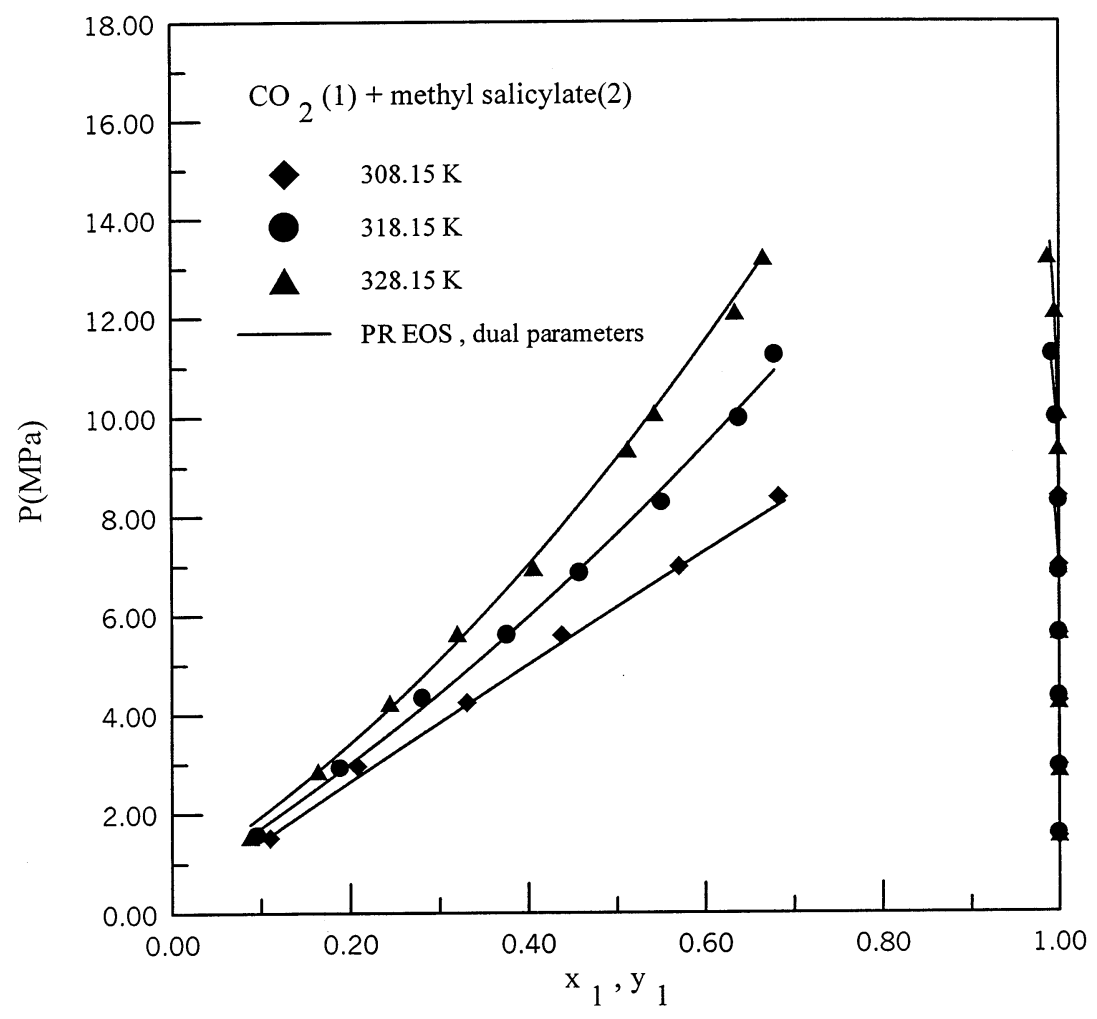

Fig. 2. VLE results of the binary mixture of $\mathrm{CO}_{2}(1)+$ methyl salicylate(2). 


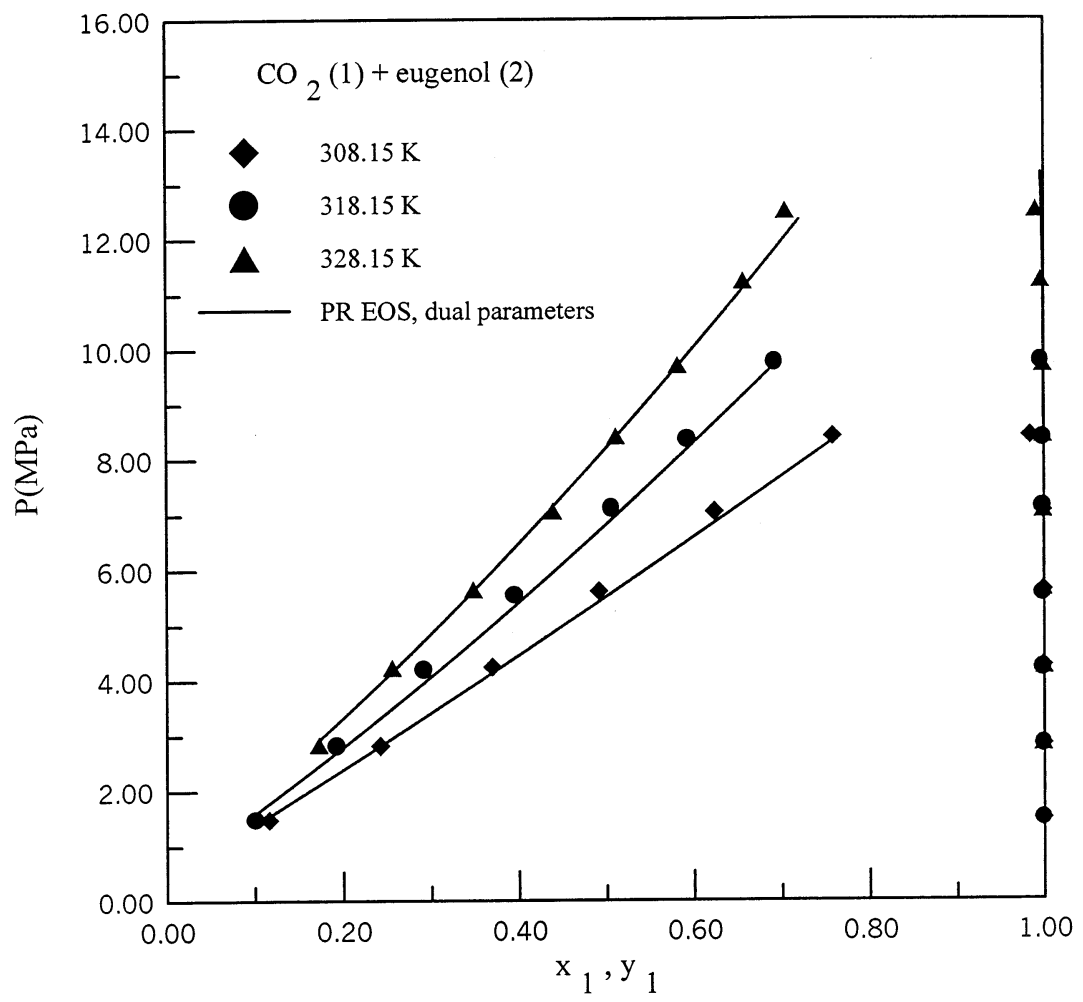

Fig. 3. VLE results of the binary mixture of $\mathrm{CO}_{2}(1)+$ eugenol(2).

$\ln \frac{f_{1}}{x_{1}}=\ln H_{1,2}^{*}+\frac{A\left(x_{2}^{2}-1\right)}{R T}+\frac{V_{1}^{\infty}\left(P-P_{2}^{\text {sat }}\right)}{R T}$

where $H_{1,2}^{*}$ is Henry's constant at the vapor pressure of the solvent $\left(P_{2}^{\text {sat }}\right), A$ the Margules constant, and $V_{1}^{\infty}$ is the partial molar volume of the gas at infinite dilution. In this study, $V_{1}^{\infty}$ is estimated from the generalized equation proposed by Brelvi and O'Connell [10] with the modified Rackett model [11] for calculating the liquid density. Carbon dioxide is a dominating component in the gas phase and its fugacity in the gas mixture $\left(f_{1}\right)$ is calculated by employing the Lewis fugacity rule:

$f_{1}=f_{1}^{0} y_{1}$

where $f_{1}^{0}$ is the fugacity of pure carbon dioxide calculated by the equation reported by Huang et al. [12]. The value of $H_{1,2}^{*}$ and the Margules constant $A$ in the KI equation were evaluated by the least squares algorithm and the results are listed in Table 5. The average absolute deviation of data regression is small and the solubility data are satisfactorily correlated by the KI equation. Henry's constants increase with temperature for a given solvent because the solubility of carbon dioxide decreases with increasing temperature.

Equation of state methods was employed to correlate the measured VLE data. The PengRobinson equation [4]:

$P=\frac{R T}{v-b}-\frac{a}{v(v+b)+b(v-b)}$

Table 6

Pure component properties used in this work ${ }^{\mathrm{a}}$

\begin{tabular}{llll}
\hline Component & $T_{\mathrm{c}}(\mathrm{K})$ & $P_{\mathrm{c}}(\mathrm{bar})$ & $\omega$ \\
\hline Carbon dioxide & $304.19 \mathrm{a}$ & $73.82 \mathrm{a}$ & $0.228 \mathrm{a}$ \\
Methyl salicylate & $701.00 \mathrm{a}$ & $40.90 \mathrm{a}$ & $0.632 \mathrm{a}$ \\
Eugenol & $778.70 \mathrm{~b}$ & $41.05 \mathrm{~b}$ & $0.592 \mathrm{c}$ \\
Diethyl phthalate & $757.00 \mathrm{a}$ & $23.30 \mathrm{a}$ & $0.763 \mathrm{a}$
\end{tabular}

a a, [19]; b, [20,21]; c, [22]. 
$a=0.45724\left(\frac{R^{2} T_{\mathrm{c}}^{2}}{P_{\mathrm{c}}}\right)\left\{1+\alpha\left[1-\left(\frac{T}{\mathrm{~T}_{\mathrm{c}}}\right)^{0.5}\right]\right\}^{2}$

$\alpha=0.37464+1.54226 \omega-0.26992 \omega^{2}$

$b=0.07780 \frac{R T_{\mathrm{c}}}{P_{\mathrm{c}}}$

and the Soave-Redlich-Kwong equation [3]:

$P=\frac{R T}{v-b}-\frac{a}{v(v+b)}$

$a=0.42747\left(\frac{R^{2} T_{\mathrm{c}}^{2}}{P_{\mathrm{c}}}\right)\left\{1+\beta\left[1-\left(\frac{T}{T_{\mathrm{c}}}\right)^{0.5}\right]\right\}^{2}$

$\beta=0.480+1.574 \omega-0.176 \omega^{2}$

$b=0.08664 \frac{R T_{\mathrm{c}}}{P_{\mathrm{c}}}$

were used to correlate the experimental results. The equation of state parameters $a$ and $b$ for each pure fluid are evaluated from its critical properties and acentric factor. The critical properties and the acentric factors for the pure compounds used in this study are listed in Table 6 .

Various mixing models were applied in this study to evaluate the equation of state parameters for mixtures. For the van der Waals one-fluid (VDW1) mixing rules with one binary parameter, the mixture parameters are expressed as:

$a_{\mathrm{m}}=\sum \sum x_{i} x_{j}\left(a_{i} a_{j}\right)^{0.5}\left(1-k_{i j}\right)$

$b_{\mathrm{m}}=\sum x_{i} b_{i}$

The volume parameter of a mixture can also be evaluated using an additional binary parameter (VDW2 mixing rule):

$b_{\mathrm{m}}=\sum \sum x_{i} x_{j} \frac{\left(b_{i}+b_{j}\right)}{2}\left(1-m_{i j}\right)$

The binary parameters are taken as temperature-independent in this study, and their optimal values are determined from data regression.

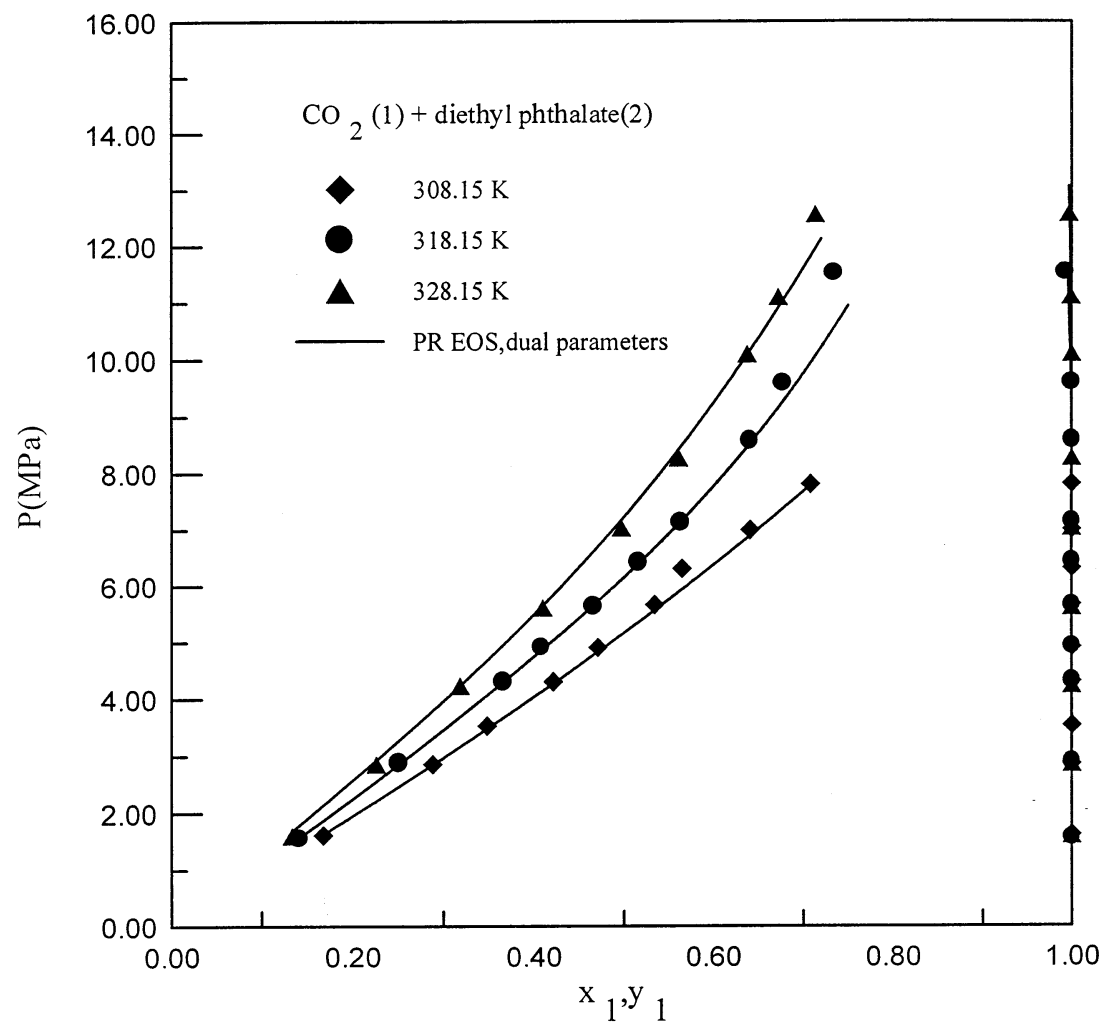

Fig. 4. VLE results of the binary mixture of $\mathrm{CO}_{2}(1)+$ diethyl phthalate(2). 


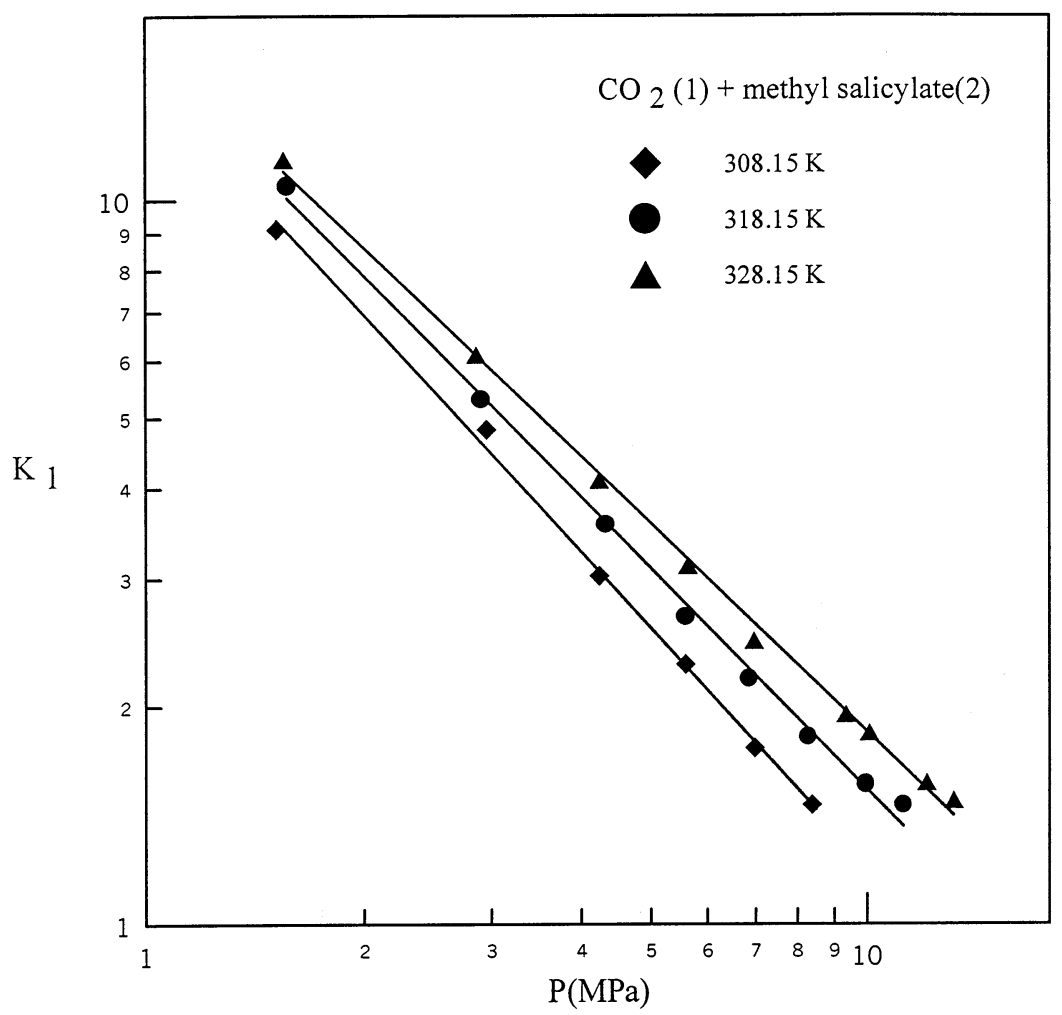

Fig. 5. Equilibrium ratios for the binary mixture of $\mathrm{CO}_{2}(1)+$ methyl salicylate(2).

Panagiotopoulos and Reid [13] assumed that the binary parameters are composition-dependent, the mixture volume parameter for an equation of state is determined by Eq. (12), and the mixture energy parameter is written as:

$a_{\mathrm{m}}=\sum \sum x_{i} x_{j}\left(a_{i} a_{j}\right)^{0.5}\left[1-k_{i j}+\left(k_{i j}-k_{j i}\right) x_{i}\right]$

This mixing rule can be applied for binary mixtures, but may suffer from the MichelsenKistenmacher syndrome [14] for multi-component systems.

Besides the traditional van der Waals type mixing models, Huron and Vidal [15] also introduced a group contribution mixing model. In this mixing model, the excess free energy calculated from an equation of state at an infinite pressure reference state is set equal to that from an activity coefficient model. The NRTL [16] and UNIQUAC [17] activity coefficient models were employed in this study with the cubic equations of state. The optimal binary parameters in the NRTL and the UNIQUAC models were regressed from the experimental VLE data. The following objective function was used in data regression:

$\mathrm{obj}=\sum\left|\frac{P_{i}^{\exp }-P_{i}^{\mathrm{cal}}}{P_{i}^{\exp }}\right|+\sum\left|y_{i}^{\exp }-y_{i}^{\mathrm{cal}}\right|$

The optimal binary parameters for various equations of state with the van der Waals type mixing rules are presented in Table 7 . It is observed that either the Peng-Robinson or SoaveRedlich-Kwong equation with dual parameters yields satisfactory results. The optimal NRTL and UNIQUAC parameters regressed from the Huron-Vidal method are shown in Table 8. The results show a relatively larger deviation than that from the van der Waals mixing rules with dual parameters. Graphical presentations of the calculated results from the Peng-Robinson equation of 
state with dual interaction parameters are also shown in Figs. 3 and 5.

\section{Conclusion}

The VLE data of three binary systems of carbon dioxide with methyl salicylate, eugenol, and diethyl phthalate are reported at 308.15, 318.15, and $328.15 \mathrm{~K}$ and pressures up to $13 \mathrm{MPa}$. The experimental data satisfy the thermodynamic consistency test. The Krichevsky-Ilinskaya equation was used to correlate the experimental data and Henry's constants are determined. The PengRobinson and Soave-Redlich-Kwong equations of state with various mixing models were also used to correlate the experimental data. It shows that both the Peng-Robinson and Soave-Rsdlich-Kwong equations of state with the van der Waals mixing rules and two optimally fitted parameters give satisfactory regression results.

\section{List of symbols}

$a, b$ parameters in the equation of state

$A$ Margules parameter in the KI equation

$K$ equilibrium ratio

$k$ binary interaction parameter in the mixing rule

$f_{1}^{0} \quad$ fugacity of carbon dioxide

$f \quad$ fugacity

$H_{1,2}^{*} \quad$ Henry constant at $P_{2}^{\text {sat }}$

$m$ binary interaction parameter in the mixing rule

$P \quad$ pressure

$R \quad$ gas constant

$T$ temperature

$V_{1}^{\infty}$ partial molar volume of a gas at infinite dilution

$v \quad$ molar volume

$x \quad$ mol fraction of liquid phase

$y \quad$ mol fraction of vapor phase

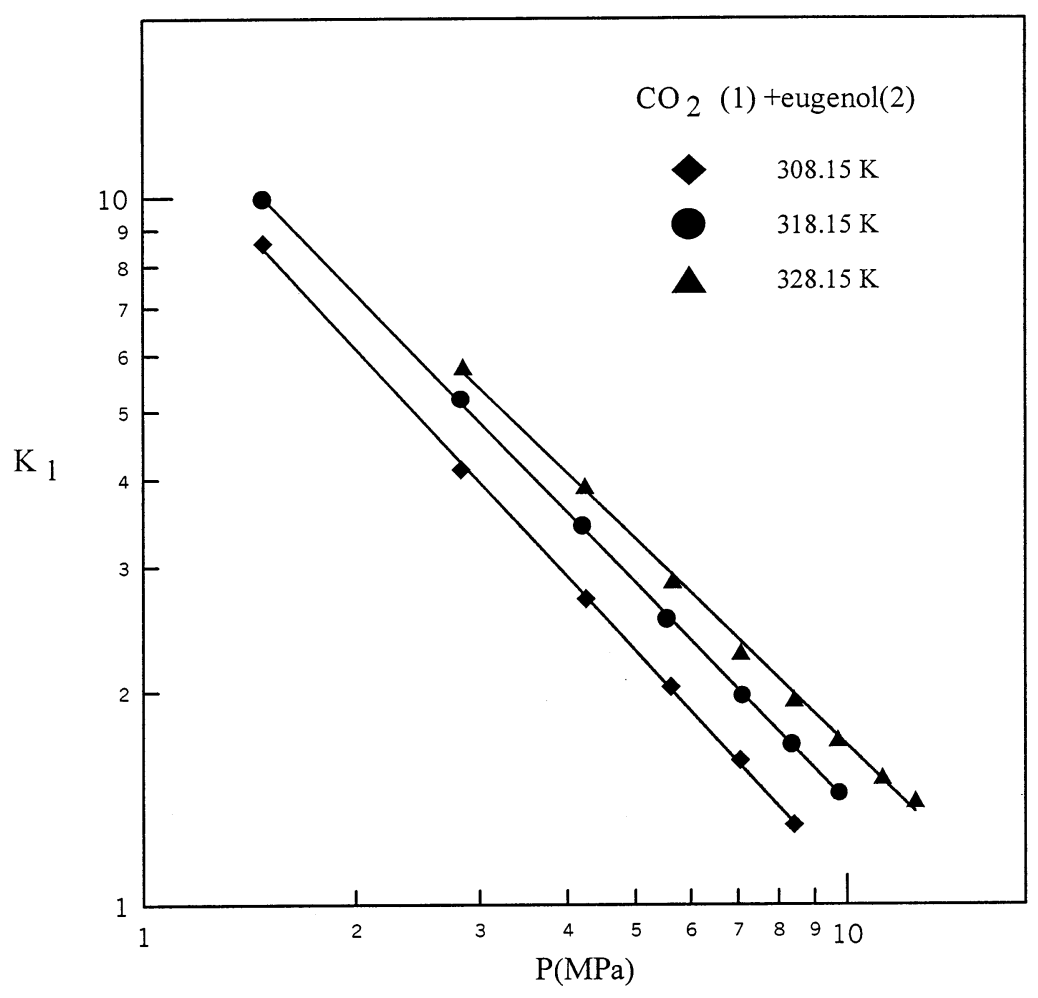

Fig. 6. Equilibrium ratios for the binary mixture of $\mathrm{CO}_{2}(1)+$ eugenol(2). 


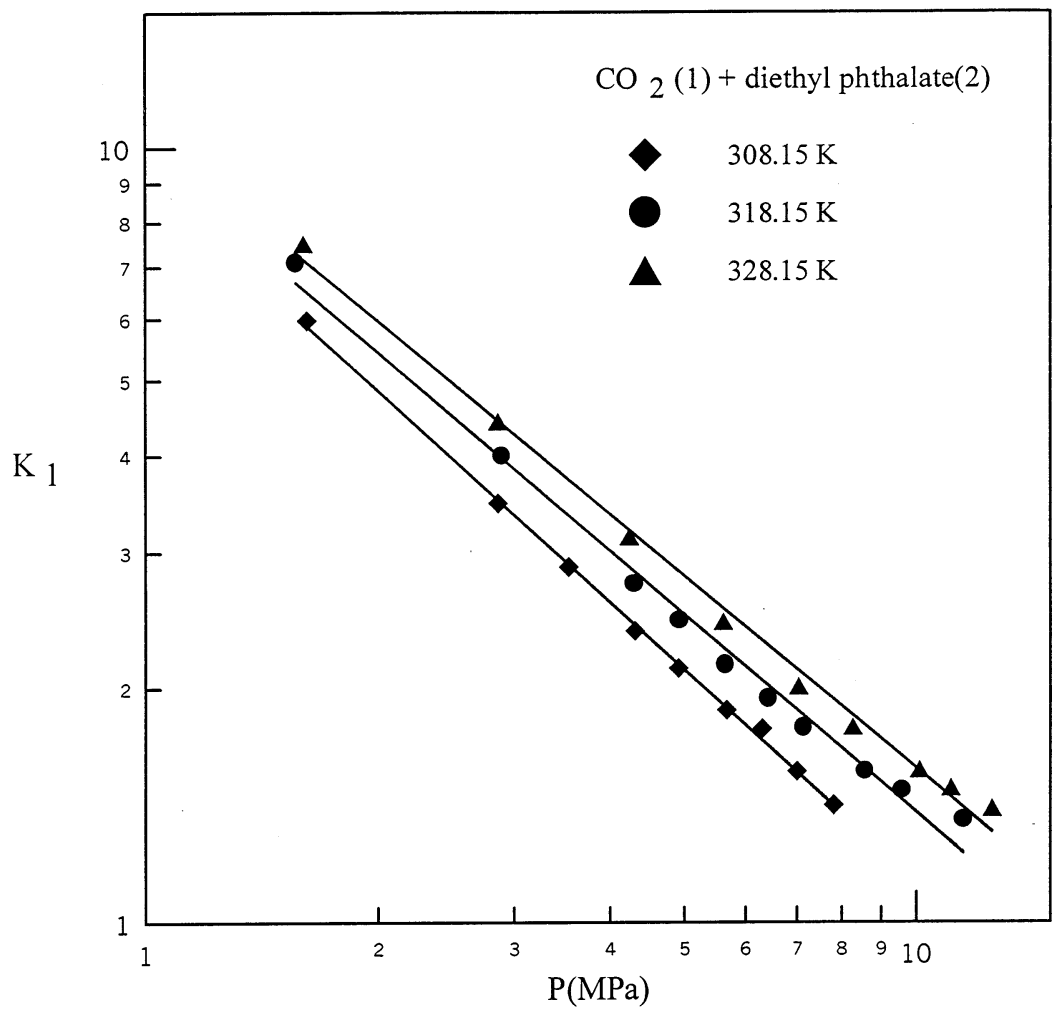

Fig. 7. Equilibrium ratios for the binary mixture of $\mathrm{CO}_{2}(1)+$ diethyl phthalate(2).

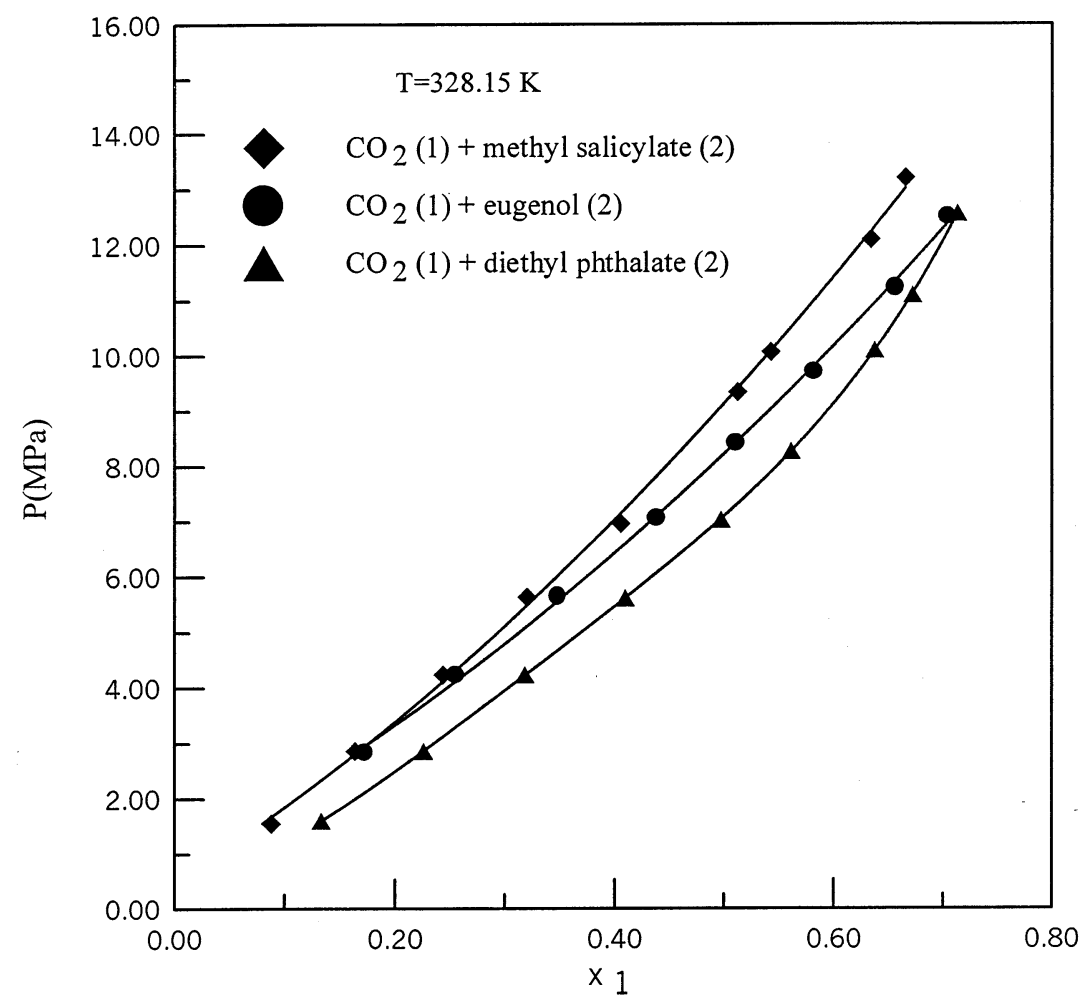

Fig. 8. Solubilities of $\mathrm{CO}_{2}$ in various compounds at $328.15 \mathrm{~K}$. 


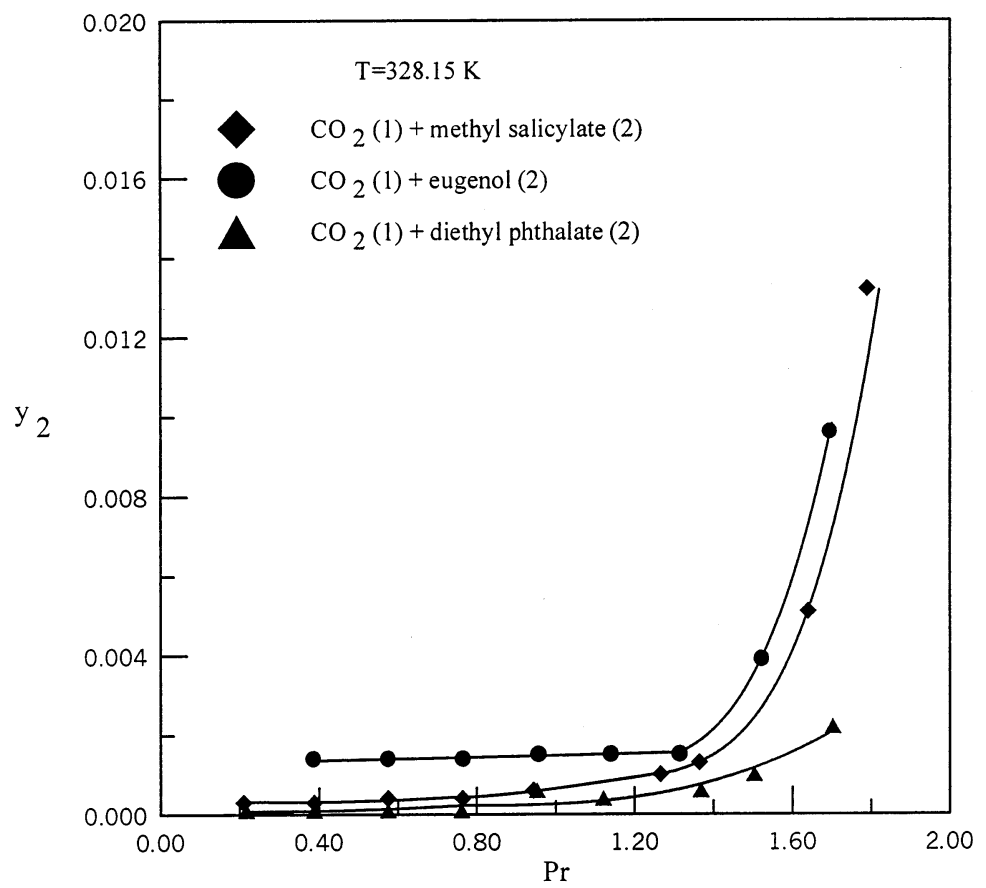

Fig. 9. Solubilities of various compounds in supercritical $\mathrm{CO}_{2}$ at $328.15 \mathrm{~K}\left(P_{\mathrm{r}}=P / P_{\mathrm{c}, \mathrm{CO}_{2}}\right)$.

Table 7

Correlated results of experimental VLE data of three binary mixtures using various EOS mixing rules ${ }^{\mathrm{a}}$

\begin{tabular}{|c|c|c|c|c|c|c|c|c|}
\hline Mixing rule & $k_{12}$ & $k_{21}$ & $m_{12}$ & $\Delta P(\%)$ & $k_{12}$ & $k_{21}$ & $m_{12}$ & $\Delta P(\%)$ \\
\hline \multicolumn{9}{|l|}{$\mathrm{CO}_{2}(1)+$ methyl salicylate } \\
\hline VDW1 & 0.043 & & & 12.5 & 0.038 & & & 12.1 \\
\hline VDW2 & 0.032 & & -0.024 & 1.5 & 0.026 & & -0.023 & 1.4 \\
\hline \multicolumn{9}{|l|}{$\mathrm{CO}_{2}(1)+$ eugenol(2) } \\
\hline VDW1 & 0.013 & & & 15.6 & 0.006 & & & 15.2 \\
\hline VDW2 & -0.001 & & -0.027 & 2.1 & -0.011 & & -0.027 & 2.1 \\
\hline Panagiotopoulos-Reid & 0.076 & 0.009 & & 2.1 & 0.069 & -0.001 & & 2.1 \\
\hline \multicolumn{9}{|c|}{$\mathrm{CO}_{2}(1)+$ diethyl phthalate(2) } \\
\hline
\end{tabular}

${ }^{\mathrm{a}} \Delta P(\%)=100 / n \sum_{i=1}^{n}\left|P^{\exp }-P^{\mathrm{cal}}\right|_{i} / P_{i}^{\exp }$. 
Table 8

Correlated results of the experimental VLE data of three binary mixtures by the Huron-Vidal mixing rules with the NRTL and the UNIQUAC activity coefficient models

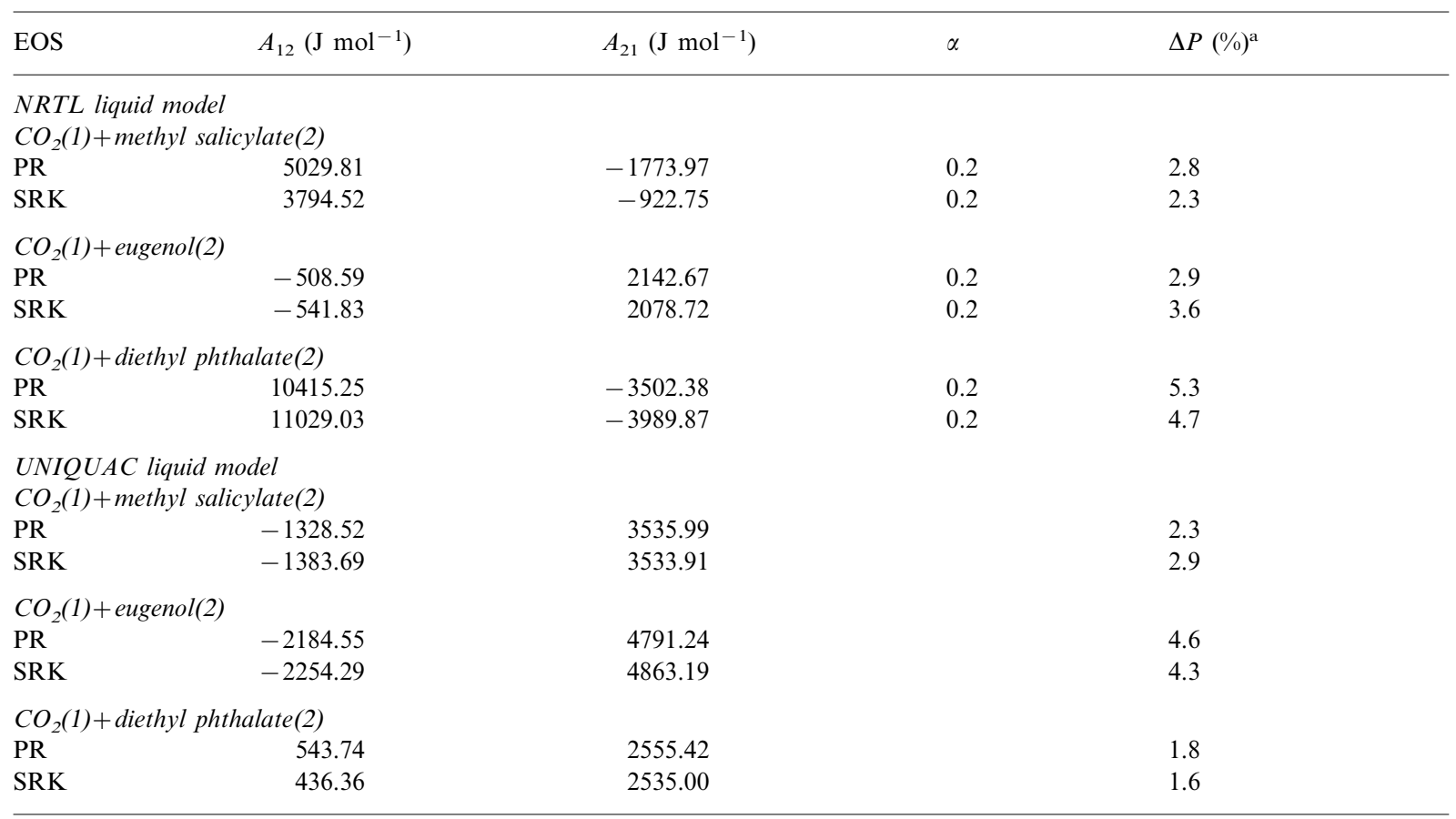

$$
{ }^{\mathrm{a}} \Delta P(\%)=100 / n \sum_{i=1}^{n}\left|P^{\exp }-P^{\mathrm{cal}}\right|_{i} / P_{i}^{\exp } .
$$

\section{Greek letters}

$\alpha, \beta$ parameters in the equations of state

$\rho$ density

$\omega$ acentric factor

\section{Subscripts}

c critical properties

$i, j \quad$ component $i$ or $j$

$\mathrm{m}$ mixture

1,2 component 1 or 2

Superscripts

cal calculated value

exp experimental data

sat saturated condition

\section{Acknowledgements}

The authors are grateful to the National Science Council, Republic of China, for supporting this research.

\section{References}

[1] I. Wichterle, J. Linek, Z. Wagner, H.V. Kehiaian, Vapor-Liquid Equilibrium Bibliographic Database, ELDATA SARL, Montreuil, 1993.

[2] Z. Wagner, Vapour-liquid equilibrium at high pressure in the system containing carbon dioxide and propyl acetate, Fluid Phase Equilib. 110 (1995) 175-182.

[3] G. Soave, Equilibrium constants from a modified Redlich-Kwong equation of state, Chem. Eng. Sci. 27 (1972) 1197-1203.

[4] D.Y. Peng, D.B. Robinson, A new two constant equation of state, Ind. Eng. Chem. Fundam. 15 (1976) 59-64.

[5] R.J. Lee, K.C. Chao, Extraction of 1-methylnaphthalene and $m$-cresol with supercritical carbon dioxide and ethane, Fluid Phase Equilib. 43 (1988) 329-340.

[6] D.E. Matschke, G. Thodos, Vapor-liquid equilibria for the ethane-propane system, J. Chem. Eng. Data 7 (1962) 232-234.

[7] T. Sako, T. Sugeta, N. Nakazawa, K. Otake, M. Sato, K. Ishihara, M. Kato, High pressure of vapor-liquid and vapor-liquid-liquid equilibria for system containing supercritical carbon dioxide, water and furfural, Fluid Phase Equilib. 108 (1995) 293-303. 
[8] D.-S. Jan, F.N. Tsai, Modeling phase behavior of carbon dioxide with aromatic solvents, Ind. Eng. Chem. Res. 30 (1991) 1965-1970.

[9] I.R. Krichevsky, A.A. Ilinskaya, Partial molar volumes of gas dissolved in liquids (the thermodynamics of dilute solution of nonelectrolytes), Acta Physicochim. USSR 20 (1945) 327-348.

[10] S.W. Brelvi, J.P. O'Connell, Corresponding state correlation for liquid compressibility and partial molar volume of gases at infinite dilution in liquids, Am. Inst. Chem. Eng. J. 18 (1972) 1239-1243.

[11] C.F. Spencer, R.P. Danner, Improved equation for prediction of saturated liquid density, J. Chem. Eng. Data 17 (1972) 236-241.

[12] F.H. Huang, M.H. Li, L.L. Lee, K.E. Starling, F.T.H. Chung, An accurate equation of state for carbon dioxide, J. Chem. Eng. Jpn. 18 (1985) 490-496.

[13] A.Z. Panagiotopoulos, R.C. Reid, New mixing rule for cubic equation of state for highly polar asymmetric systems, ACS Symp. Ser. 300 (1986) 571-582.

[14] M.L. Michelsen, H. Kistenmacher, On composition-dependent interaction coefficients, Fluid Phase Equilib. 58 (1990) 229-230.

[15] M.J. Huron, J. Vidal, New mixing rules in simple equation of state for representing vapor-liquid equilibria of strongly non-ideal mixtures, Fluid Phase Equilib. 3 (1979)
255-271.

[16] H. Renon, J.M. Prausnitz, Local compositions in thermodynamic excess functions for liquid mixture, Am. Inst. Chem. Eng. J. 14 (1968) 135-144.

[17] D.S. Abrams, J.M. Prausnitz, Statistical thermodynamics of liquid mixture: a new expression for the excess Gibbs energy of partly or completely miscible system, Am. Inst. Chem. Eng. J. 21 (1968) 116-128.

[18] D.R. Lide, H.P.R. Frederikse, CRC Handbook of Chemistry and Physics, 75th ed., CRC Press, Boca Raton, FL, 1994.

[19] T.E. Daubert, R.P. Danner, Physical and Thermodynamic Properties of Pure Chemicals: Data Compilation, Hemisphere, New York, 1989.

[20] D. Ambrose, Correlation and estimation of vapor-liquid critical properties I critical temperature of organic compounds, NPL Report Chem. 92, National Physical Laboratory, Teddington, UK, September 1978, corrected March 1980.

[21] D. Ambrose, Correlation and estimated of vapor-liquid critical properties II critical pressure and volume of organic compounds, NPL Report Chem. 98, National Physical Laboratory, Teddington, UK, 1979.

[22] B.I. Lee, M.G. Kesler, A generalized thermodynamic correlation based on three-parameter corresponding states, Am. Inst. Chem. Eng. J. 21 (1975) 510-527. 